\title{
Effect of Process Control Agents on Fe-15at.\%Nb powder during Mechanical Alloying
}

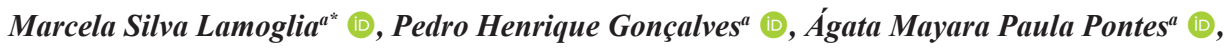 \\ Leandro Bernardes Serrano ${ }^{a}$ (1), Gilbert Silva ${ }^{\circledR}$ (1), Antonio Augusto Araújo Pinto da Silva ${ }^{\circledR}(1)$ \\ ${ }^{a}$ Universidade Federal de Itajubá (UNIFEI), Instituto de Engenharia Mecânica, Avenida BPS, 1303, \\ 37500-903, Itajubá, MG, Brasil.
}

Received: June 28, 2021; Revised: December 06, 2021; Accepted: December 07, 2021

\begin{abstract}
In this paper, $\mathrm{Fe}-15$ at. $\% \mathrm{Nb}$ alloys were produced from high purity $\mathrm{Fe}$ (min. $99.8 \%$ ) and $\mathrm{Nb}$ (min. 99.8\%) powders via a mechanical alloying process. The effects of different Process Control Agents (i.e., methanol, hexane, and stearic acid) were investigated with powder morphologies, particle size distribution, and phase formation, and were sampled after up to 80 milling hours at $350 \mathrm{rpm}$. The powder morphologies and particle sizes were evaluated using scanning electron microscopy and laser diffraction analysis, respectively, and phases were identified via X-ray powder diffractometry. The results demonstrate for all conditions that, in the early stages, there was significant particle agglomeration due to the ductile-ductile feature of $\mathrm{Fe}$ and $\mathrm{Nb}$ powders, and latter an amorphization trend up to 80 milling hours. Methanol was the most efficient Process Control Agent in terms of avoiding cold welding, reducing of agglomeration, particle size distribution, reducing contamination and crystallinity reduction rate.
\end{abstract}

Keywords: $\mathrm{Fe}-\mathrm{Nb}$ alloy, Mechanical Alloying, Process Control Agent, Phase formation, Powder Metallurgy.

\section{Introduction}

Mechanical Alloying (MA) processes are characterized by repeated cold welding and powder particles fragmentation in high-energy ball mills. This welding-fracturing process eases diffusion and allows for alloy formations.

Of the known advantages of MA, we can mention: (1) increased Kinetic phase formation; (2) phase formation with nanometric dimensions; (3) metastable conditions, enhancing solubility for values beyond the thermodynamic limit; (4) metastable phase formation, including solid solutions, and (5) amorphous alloy formation ${ }^{1-3}$. Details for these processes have been well described in literature, by Suryanarayana $a^{1,2,4,5}$, and El-Eskandarany ${ }^{6,7}$, for example.

Studying Fe-Nb binary system alloys via the MA process is important because it can provide alternative processes, like viable results for better understanding the system phase equilibrium, and for many alloy families based on $\mathrm{Fe}-\mathrm{Nb}^{8,9}$. Some works have detailed this ${ }^{10-19}$. Most studies on $\mathrm{Fe}-\mathrm{Nb}$ systems $^{10,12,13,15-18}$ deal with systemically studying phase amorphization modes via the MA process, using milling times varying from 30 minutes to 70 hours. Povstugar et al. ${ }^{13}$, in addition to using MA, developed a heat treatment at $700{ }^{\circ} \mathrm{C}$. However, MA and heat treatment times were not specified for any phase that had been obtained. Vélez et al. ${ }^{15-}$ ${ }^{17}$ published three works related to obtaining $\mathrm{Fe}-\mathrm{Nb}$ alloys via $\mathrm{MA}$, based on magnetic property studies that used two heat treatments seeking LAVES $\left(\mathrm{Fe}_{2} \mathrm{Nb}\right)$ phase formation. Roy et al. ${ }^{14}$, analyzed the magnetic behavior of the LAVES amorphous phase prepared via MA. They found that the

*e-mail: marcelalamoglia@unifei.edu.br phase had paramagnetic characteristics. Blázquez et al. ${ }^{19}$, developed a comparative analysis of the necessary milling time for $\mathrm{Fe}-30 \mathrm{at} . \% \mathrm{Nb}$ and $\mathrm{Fe}-30 \mathrm{at} . \% \mathrm{Zr}$ alloy amorphization and the respective magnetic properties. They stated that more investigations would be needed to determine the complete $\mathrm{Fe}-\mathrm{Nb}$ system phase diagram.

PCA introduced during MA has been well established a mechanism for preventing excessive cold welding, due to reduced cleaving surface energy, leading to more effective particle size reductions ${ }^{20,21}$. Besides, PCA has been reported preventing excessive friction between spheres and jars, mitigating wear consequentially decreasing contamination from milling tools ${ }^{21}$ which is desirable ${ }^{22,23}$ especially to steel industry ${ }^{24,25}$. As far as we know, there are no studies in literature on the PCA effect on MA in Fe-Nb system alloys. Here, the effects of different PCAs (methanol, hexane, stearic acid) on mechanical alloying for $\mathrm{Fe}-15 \mathrm{at} . \% \mathrm{Nb}$ alloy were studied, in terms of phase formation, particle size, distribution, and shape.

\section{Fe-Nb System \& Fe-15\% at. Nb Alloy}

The most recent $\mathrm{Fe}-\mathrm{Nb}$ equilibrium phase diagram (Figure 1) proposed by Liu et al. ${ }^{26}$ has two stable intermetallic phases: (1) $\mathrm{Fe}_{2} \mathrm{Nb}$ (LAVES) phase, which has congruent formation $\left(1646{ }^{\circ} \mathrm{C}\right)$, with $\mathrm{C} 14$ structures and solubility ranging between $25\left(1373{ }^{\circ} \mathrm{C}\right)$ and $33\left(1523{ }^{\circ} \mathrm{C}\right)$ at. $\% \mathrm{Nb}$; and $(2) \mathrm{Fe}_{7} \mathrm{Nb}_{6}(\mu)$ phase with peritectic formation $\left(1523^{\circ} \mathrm{C}\right)$, $\mathrm{D} 8_{5}$ structures and solubility ranging between $41\left(1523^{\circ} \mathrm{C}\right)$ and $51\left(1508^{\circ} \mathrm{C}\right)$ at. $\% \mathrm{Nb}$. The system also has two eutectic 
reactions, one between phases $(\delta \mathrm{Fe})$ and $\mathrm{Fe}_{2} \mathrm{Nb}$, and the other between phases $\mathrm{Fe}_{7} \mathrm{Nb}_{6}$ and $(\mathrm{Nb})$. Table 1 summarizes the crystallographic data for the stable solid phases in the $\mathrm{Fe}-\mathrm{Nb}$ system $^{27,28}$. Fe-15at.\%Nb alloy composition was selected in this study because of its importance for Fe alloy industries and for new alloys that are based on $\mathrm{Fe}^{26,27}$.

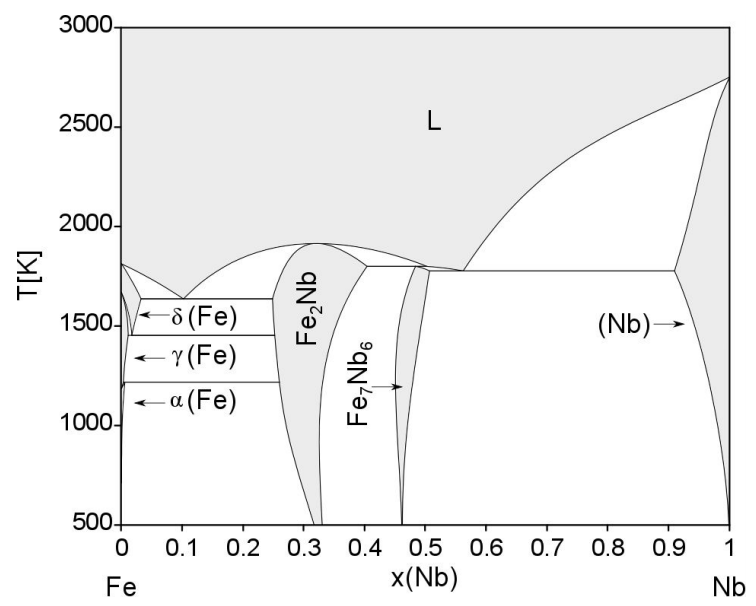

Figure 1. Phase diagram of the $\mathrm{Fe}-\mathrm{Nb}$ system calculated with parameters optimized by Liu et al. $\left[{ }^{26}\right]$.

\section{PCA Effect}

If the MA process is not controlled, excessive cold welding and high ductile particles agglomeration can occur. It is possible to introduce organic material to modify the powder surface. These are called surfactants or Process Control Agents (PCA), like methanol ${ }^{20,29,30}$, hexane ${ }^{31}$, stearic acid ${ }^{20,30,31}$, oxalic acid, boric acid, alumina, ethanol, polyethylene glycol, etc., added to balance the reactions ${ }^{32}$. These are added at $1 \%$ and $5 \%$ of the total mix, because the type and amount of PCA influences the size and shape of thin particles during milling ${ }^{7,33}$.

PCA molecules are based on hydrocarbon chains, which have polar functional groups. They interact with metallic powder polar groups creating covalent bonds between adsorbates (PCA) and absorbing surfaces (material). As a result, molecules form a monolayer on the powder surface. Molecular chains act as barriers around the particles to protects them from agglomeration ${ }^{21,34}$.

Figure 2 shows PCA's role in the MA process, recovering the whole powder surface. Homogeneous PCA distribution during MA is known to be influenced by the physical state of matter (solid, liquid and gas) at room temperature. Solid state PCA (Figure $3 \mathrm{~b}$ ) at the start of milling may not be properly distributed, covering powder particles, while liquid PCA (Figure 3a) can spread quickly ${ }^{21,33}$.

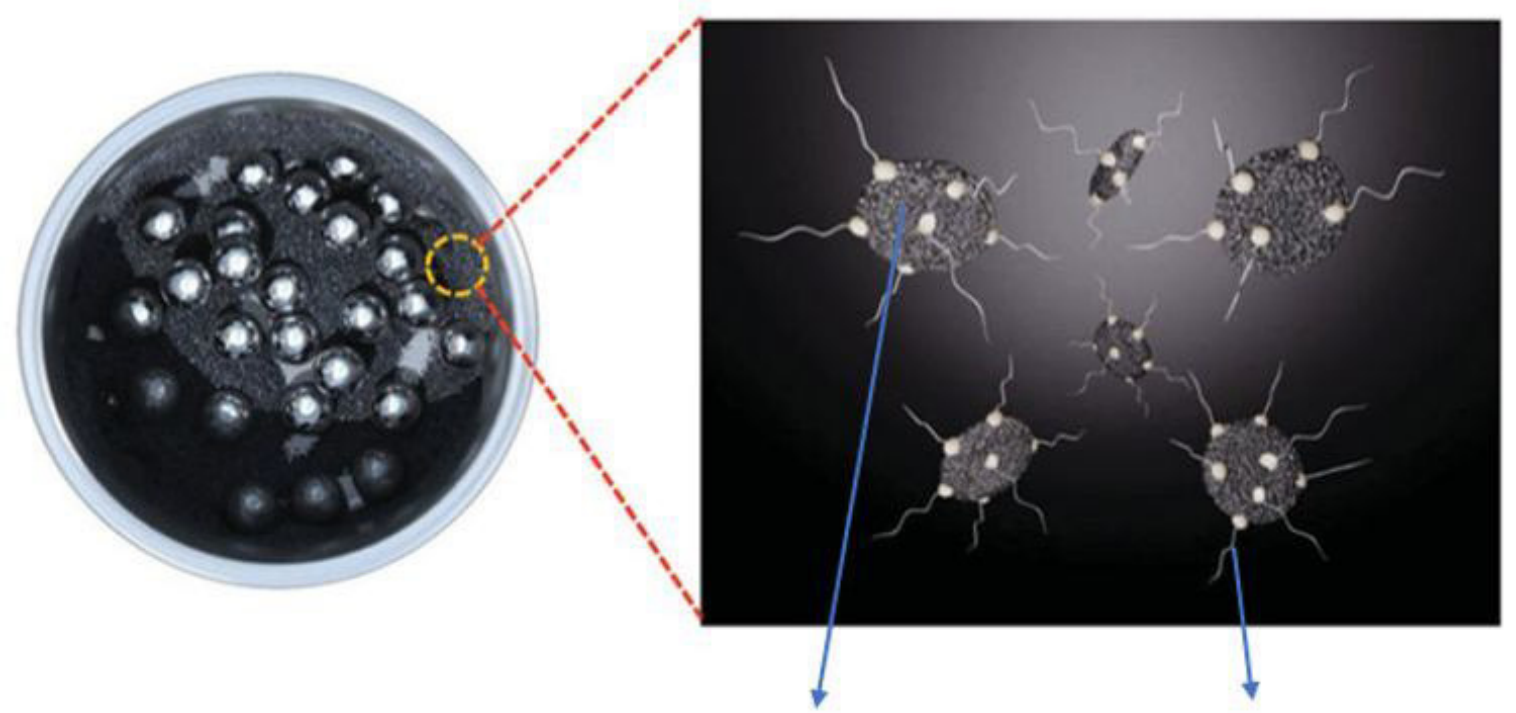

Adsorbent

Adsorbate

Figure 2. Schematic of PCA in the MA process. Adapted from $\left[{ }^{15}\right]$.

Table 1. Crystallographic information for stable solid phases in the Fe-Nb system [27,28].

\begin{tabular}{ccccc}
\hline Phase & Struk* $^{*}$ & Pearson Symbol & Space Group & Prototype \\
\hline$(\boldsymbol{\alpha F e}),(\boldsymbol{\delta} \mathbf{F e}),(\mathbf{N b})-\mathbf{B C C}$ & $\mathrm{A} 2$ & $\mathrm{cI} 2$ & $\mathrm{Im} \overline{\mathbf{3}} \mathrm{m}$ & $\mathrm{W}$ \\
\hline$(\gamma \mathbf{F e})-\mathbf{F C C}$ & $\mathrm{A} 1$ & $\mathrm{cF} 4$ & $\mathrm{Fm} \overline{3} \mathrm{~m}$ & $\mathrm{Cu}$ \\
\hline $\mathbf{F e}_{2} \mathbf{N b}($ Laves$)$ & $\mathrm{C} 14$ & $\mathrm{hP} 12$ & $\mathrm{P} 63 / \mathrm{mmc}$ & $\mathrm{MgZn}_{2}$ \\
\hline $\mathbf{F e}_{7} \mathbf{N b}_{6}-\boldsymbol{\mu}$ & $\mathrm{D} 8_{5}$ & $\mathrm{hR} 13$ & $\mathrm{R} \overline{3} \mathrm{~m}$ & $\mathrm{Fe}_{7} \mathrm{~W}_{6}$ \\
\hline
\end{tabular}


In general, they decompose during milling, or interact with powder to generate compounds, and these are incorporated as inclusions and/or dispersions in powder particles during milling. Hydrocarbons, which contain hydrogen and carbon, carbon and oxygen, may introduce carbon and/or oxygen in powder particles, resulting in carbide formation and oxides, which will be evenly distributed on the matrix ${ }^{7,21,30}$. The latter may not necessarily be harmful to alloy systems, since they can strengthen material dispersion resulting in higher resistance and hardness $s^{7,21,33}$.

\section{Experimental Procedure}

\subsection{Preparing the alloys}

Raw materials were pure $\mathrm{Nb}$ ( $\min .99 .8 \%$ ) sized between 2 to $20 \mu \mathrm{m}$ (determined via laser diffraction granulometric analysis) and pure Fe powders (min. 99.8\%), obtained via hydrogenation-dehydrogenation (HDH), with sized less than $25 \mu \mathrm{m}$, according to the material's datasheet.

Elemental powders ( $\mathrm{Fe}$ and $\mathrm{Nb}$ ) were weighed according $\mathrm{Fe}-15 \mathrm{at} . \% \mathrm{Nb}$ (at\%) composition with $60 \mathrm{~g}$ total mass. The mixtures were subjected to four different conditions: (1) Fe-15at.\%Nb reference (without PCA); (2) Fe-15at.\% $\mathrm{Nb}$ with methanol; (3) Fe-15at.\%Nb with hexane; and (4) Fe-15at.\%Nb with stearic acid (SA). Table 2 shows PCA proportions and properties.

The MA process carries out in a Noah-Nuoya ${ }^{\circledR}$ NQM $0.2 \mathrm{~L}$ planetary ball mill with parameters according to Table 3 . The capacity was $200 \mathrm{~g}$ together with the milling spheres, and argon gas N4.0 (99.998\% purity) was introduced inside of the milling jars to avoid oxidation. The milling rotation speed was $350 \mathrm{rpm}$, the ball to powder weight ratio was 15:1, and 60 grams of powder were used for each milling process. Samples for all conditions were collected for analysis after 20, 40, 60 and 80 milling hours.

\subsection{Characterization of alloys}

\subsubsection{Laser diffraction granulometric analysis}

Before the granulometric analysis, samples were submitted to an ultrasound bath (Alfa Mare model ALTsonic) for 5 minutes, in a water and glycerin solution, to guarantee

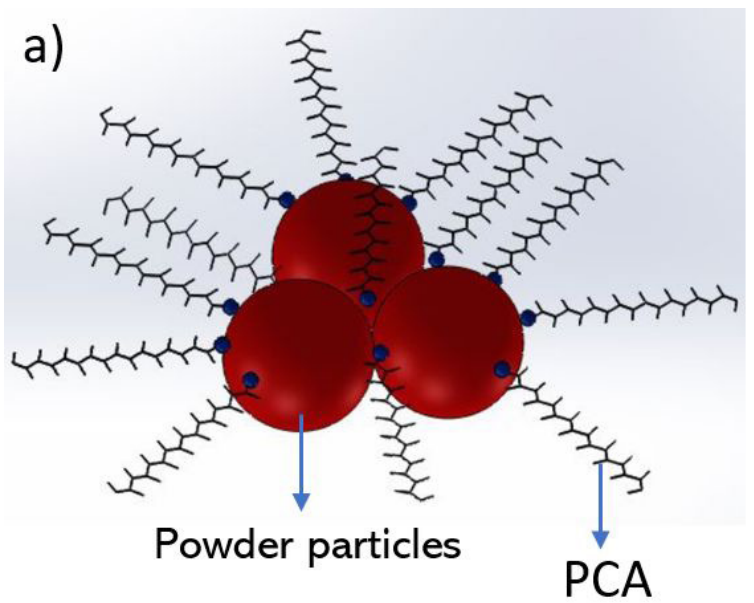

particle dispersion. The laser diffraction granulometric test was performed using a Microtec Flex S3500 that uses software analysis based on an optical model derived from Mie's Spreading Theory. To express a single value for the measured particle, an equivalent sphere value was adopted, defined here as average diameter.

\subsubsection{Scanning Electron Microscopy}

Micrographs were obtained via a Scanning Electron Microscope in the Secondary Electron mode using a Carl Zeiss $\mathrm{EVO}^{\circledR}$ MA15 with $20 \mathrm{kV}$ acceleration for morphologies and particle size distribution analysis.

\subsubsection{X-ray diffractometry}

Phase identification was performed using X-ray powder diffractometry $(\mathrm{XRD})$ with a Panalytical $\mathrm{X}^{\prime}$ Pert Pro ${ }^{\circledR}$ and $\mathrm{CuK} \alpha$ radiation $(\lambda=0.154056 \mathrm{~nm})$ at $40 \mathrm{kV}$ and $30 \mathrm{~mA}$. The analysis was performed at a $2 \theta$ angle from $30^{\circ}$ to $90^{\circ}$, with a $0.02^{\circ}$ step size, and a 2 -second counting time per step range. Phases were identified by comparing peak positions with simulated diffractograms using the PowderCell Software program $^{35,36}$, and crystallographic information from by Villars and Calvert ${ }^{27,37}$.

Table 2. Amounts used, corresponding to PCA physical properties $\left[{ }^{30}\right]$.

\begin{tabular}{ccccc}
\hline PCA & $\begin{array}{c}\text { Molecular } \\
\text { formula }\end{array}$ & $\begin{array}{c}\text { Melting } \\
\text { point }\left({ }^{\circ} \mathbf{C}\right)\end{array}$ & $\begin{array}{c}\text { Boiling } \\
\text { point }\left({ }^{\circ} \mathbf{C}\right)\end{array}$ & Amount \\
\hline Methanol & $\mathrm{CH}_{3} \mathrm{OH}$ & -98 & 65 & $3 \mathrm{ml}$ \\
\hline Hexane & $\mathrm{C}_{6} \mathrm{H}_{14}$ & -95 & 68 & $3 \mathrm{ml}$ \\
\hline $\begin{array}{c}\text { Stearic } \\
\text { acid }\end{array}$ & $\mathrm{C}_{18} \mathrm{H}_{36} \mathrm{O}_{2}$ & 69 & 232 & $1 \mathrm{~g}$ \\
\hline
\end{tabular}

Table 3. Experimental parameters in the MA process.

\begin{tabular}{cc}
\hline Milling parameter & Values \\
\hline Rotational speed & $350(\mathrm{rpm})$ \\
\hline Ball to powder ratio & $15: 1$ \\
\hline Time & $20,40,60$ and $80(\mathrm{~h})$ \\
\hline Downtime & 15 minutes $/$ hour \\
\hline Shielding gas & Argon \\
\hline Spheres diameters & $6.0-12.0-18.0(\mathrm{~mm})$ \\
\hline
\end{tabular}

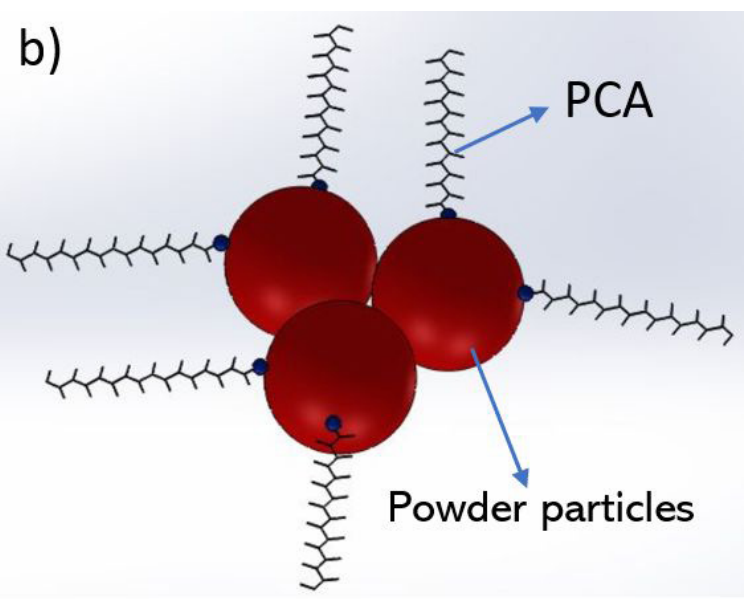

Figure 3. Schematic of PCA absorption difference (a) PCA interaction in a liquid state with particles in the MA process (b) PCA interaction in a solid state with particles in the MA process. 
Refining was applied to reduce XRD variation, using a Smoothing function form the Origin software program (version 9.0), and the gauss method for 15 data points.

Rietveld refinement was performed using the GSAS 2 software program. The pseudo-Voigt function was chosen because it was the most useful in describing the profiles of diffraction lines in the Fe- $\alpha$ peak (110), which is the most important profile in the diffractogram. The crystallite sizes and lattice parameter distortion phases were determined using the Scherer method, described $\mathrm{in}^{38-40}$. This method uses the following formula to determine the crystallite size:

$$
\mathrm{FWHM}=(k x \lambda) /(D x \cos \theta)
$$

Where FWHM is the full width at the half-maximum diffraction peak, $k$ is the shape constant $(0.9 \text { for polycrystalline })^{41}, \lambda$ is the radiation wavelength $(0.15405 \mathrm{~nm}), D$ is the crystallite size, and $\theta$ is the Bragg angle.

\section{Results and Discussion}

\subsection{Average particle size}

Figure 4 shows the average particle sizes under all conditions, i.e., different PCAs and the reference (no PCA), per milling time (20, 40, 60 and 80 hours) obtained from Laser diffraction analysis. We should note that measurement errors were minor compared to the values, so the error bars in Figure 4 are in the same scale as the symbols.

The initial particle average sizes were $\sim 15 \mu \mathrm{m}$. After 80 milling hours, for all conditions, similar particle sizes $(\sim 20 \mu \mathrm{m})$ were obtained. In general, we observed increases in average particle size in the initial milling stages, followed by refinement. This was expected due to cold welding at the beginning of the milling stage, followed by particle fractures in later stages when static balance occurs between cold welding and fractures, and average particle size is expected to remain the same ${ }^{7}$. Details on the different conditions are discussed below.

The reference sample (pure) showed increased average particle sizes in the initial milling stages, $63.3 \pm 0.3 \mu \mathrm{m}$ for 20 hours, $93.4 \pm 0.5 \mu \mathrm{m}$ for 40 hours, and after 60 hours the particles were refined to $73.6 \pm 0.6 \mu \mathrm{m}$ and $28.8 \pm 0.1 \mu \mathrm{m}$ for 60 and 80 hours, respectively.

The milled sample with methanol PCA resulted in $27.7 \pm 0.3 \mu \mathrm{m}$ at 20 hours and $32.9 \pm 0.3 \mu \mathrm{m}$ at 40 hours. The largest average particle size was $40.8 \pm 0.3 \mu \mathrm{m}$ at 60 hours, suggesting that cold welding occurred between 20 and 60 hours, along with slightly increased average sizes. Particle fractures started after 60 hours, stabilizing average size between 60 and 80 hours, reaching $19.8 \pm 0.2 \mu \mathrm{m}$ at 80 hours. The few variations among average particle sizes during the analyzed periods come from using liquid methanol, allowing for more PCA absorption on the particle surfaces in the first hours of the MA, in consequence reducing cold welding effects.

The milled samples containing liquid hexane PCA showed different characteristics compared to the previous tests. Cold welding occurred between 20 and 40 hours, and average particle size was $56.1 \pm 0.3 \mu \mathrm{m}$ at 20 hours and remained stable at $57.7 \pm 0.5 \mu \mathrm{m}$ at 40 hours. At 60 hours, the value

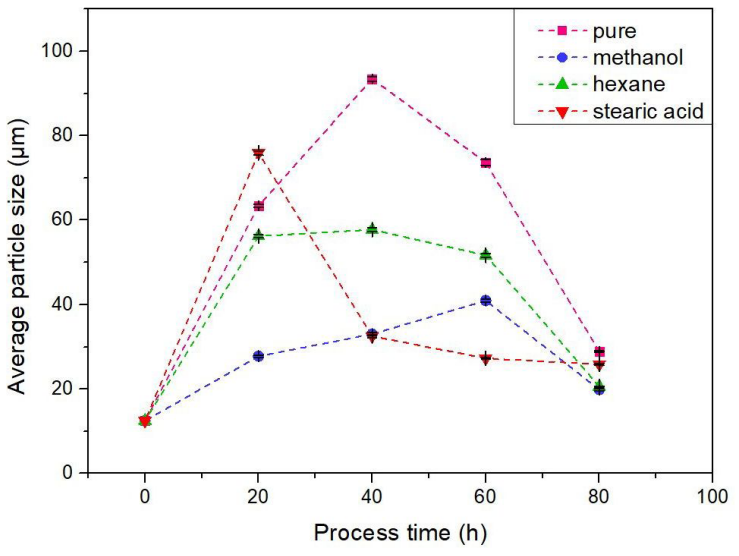

Figure 4. Average Fe-15at.\%Nb alloy particle size according to per PCA and milling time.

decreased 51.6 $\pm 0.4 \mu \mathrm{m}$, representing initial fractures, and at 80 hours it reached $20.5 \pm 0.1 \mu \mathrm{m}$ at the end of the process.

For the sample with stearic acid at 20 hours MA the particles were $75.8 \pm 0.4 \mu \mathrm{m}$ size, decreasing in the following periods to $32.5 \pm 0.3 \mu \mathrm{m}$ at $40 \mathrm{~h}, 27.2 \pm 0.1 \mu \mathrm{m}$ at $60 \mathrm{~h}$, until stabilizing around $25.8 \pm 0.1 \mu \mathrm{m}$ at $80 \mathrm{~h}$. This is, probably, due to the solid state of powder PCA that may not be well distributed at the beginning of the milling process, resulting in less efficient powder particle absorption compared to liquid $\mathrm{PCA}^{21,42}$. Thus, solid agents cause more cold welding at the beginning of the MA, as was seen in this sample.

Based on this analysis and considering that cold welding is a phenomenon to be avoided in MA process, methanol is the most efficient PCA (among the analyzed) for that purpose. This behavior was expected and reported in other studies due to using liquid methanol and hexane, allowing for more PCA absorption on the particle surfaces at the beginning of the MA, and consequently, mitigating cold welding. This mechanism is described in detail by ${ }^{20,21,43-46}$.

\subsection{Particle shapes and granulometric distribution}

The particle morphology analysis focused on the final milling stage, i.e., after 80 hours, because it is expected to present reduced agglomeration and superior particle homogeneity. Particle shapes and morphology were analyzed using comparative methods given by the German classification ${ }^{47}$. Figure 5 shows the micrographs of the alloys after 80 milling hours. Refence (without PCA), hexane and stearic acid samples showed particle shapes in flakes (Figures 5a, 5c and 5d), while the methanol sample had polygonal shapes (Figure $5 \mathrm{~b}$ ).

The reference sample had more agglomerations in size and quantity (Figure 5a), compared to the other samples. This occurs due to the PCA ductile material, which undergoes plastic deformation under compressive loads during the MA process, causing cold welding, and consequently more agglomerations (and increased average particle size, as seen at Figure 4) ${ }^{33,48,49}$.

Methanol PCA (Figure 5b) and hexane PCA (Figure 5c) samples showed that agglomerates were significantly lower 
compared to the reference sample (Figure 5a), and the sample with stearic acid (Figure 5d).

Figure 6 shows the particle size distribution under all conditions. With respect to the reference sample (Figure 6a), we can see growing asymmetric bimodal distribution, meaning population concentration composed of fine particles has been reduced. Therefore, there were more rugged particles and agglomerations. Figure $6 \mathrm{~b}$ shows a histogram of methanol PCA, with three particle populations (trimodal), and predominant medium sized particles. By analyzing the hexane PCA samples, we noticed decreased asymmetric bimodal distribution, because of larger population concentrations if formed by fine particles, while the other population was characterized by rough particle or agglomerates (Figure 6c). The stearic acid sample (Figure 6d) also showed decreased asymmetric bimodal distribution, although its lower left peak is more scattered. As already stated, this PCA was introduced in mill in a solid state and could not dissolve nor overlay the whole surface during the 80 hours process, to counteract agglomeration.

In terms of the characteristics discussed in the present section, the methanol PCA was considered the more efficient PCA, due its wider population of particle sizes and lower degrees of agglomeration. This conclusion is based on the needs of the subsequent stages of the MA process that commonly includes pressing and particle packing that tends to be more efficient when a wider distribution of particles is present ${ }^{50}$.

\subsection{X-ray diffractometry}

From XRD diffractograms, we observed an amorphization process with increased milling times for all milling conditions. The amorphization of the microstructure is characteristic of MA processes $^{51,52}$, and can be detected using XRD diffractograms, given the decreased intensity and enlarged peaks. This occurs because MA, which is associated with severe non-uniform plastic deformation in the lattice parameter, results in more structural defects (dislocations, vacancies, grain boundaries, etc.), decreasing the long-range order ${ }^{53,54}$. Crystallite average size and lattice parameter variations were also analyzed via Rietveld refining, as a function of milling time, with the $\mathrm{Fe}-\alpha$ phase reference position (110).

Figure 7 shows the X-ray diffractogram for the alloys without PCA. One can note the presence of Fe- $\alpha$ during the whole MA process, and the WC phase comes from tungsten carbide spheres.

Figure 8 shows details the Fe- $\alpha$ (110) peak. Besides increased with increased milling times, generally associated
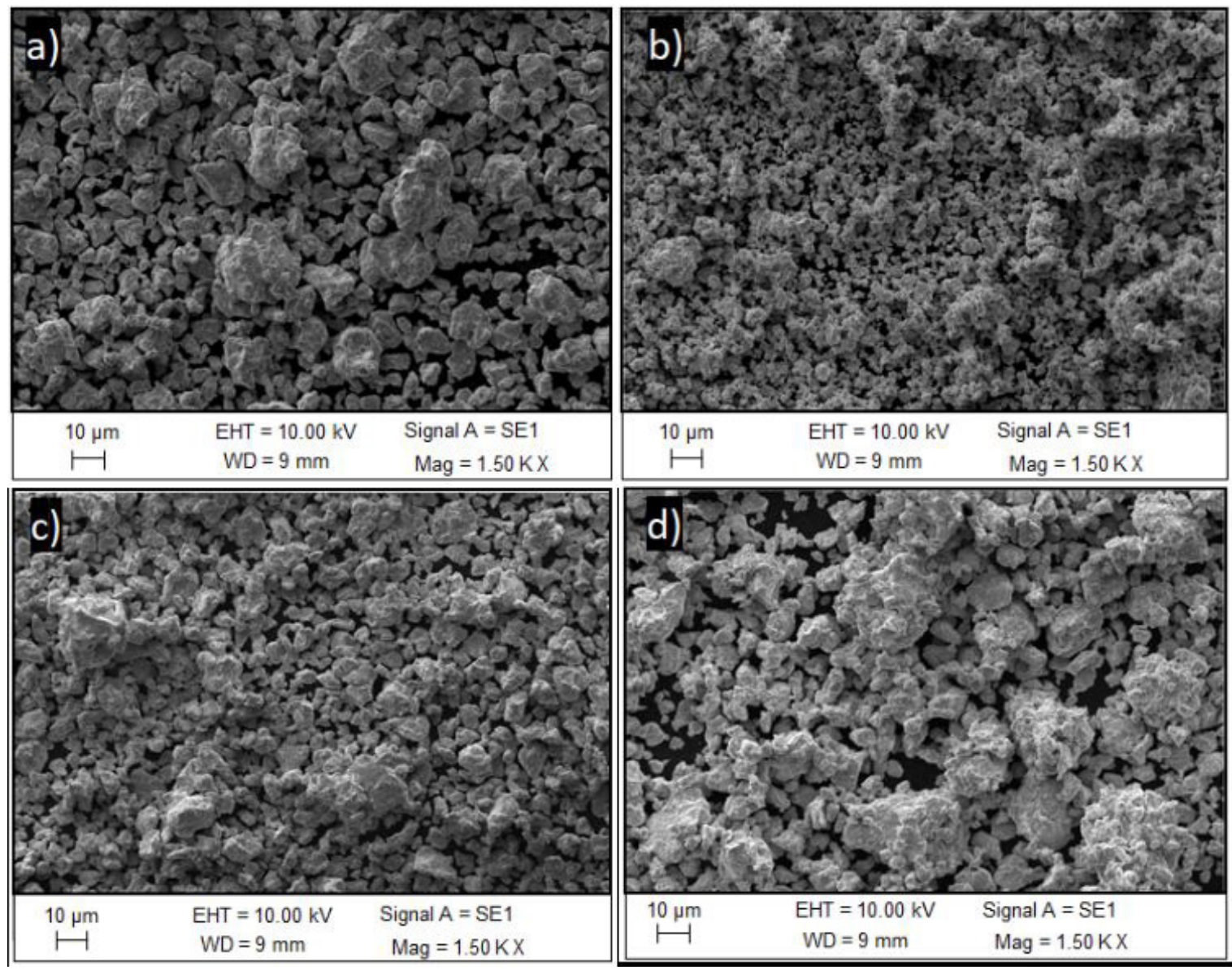

Figure 5. SEM/SE micrographs of alloys (a) Fe-15at.\%Nb samples without PCA (reference), (b) Fe-15at.\%Nb samples with methanol PCA, (c) Fe-15at.\%Nb samples with hexane PCA, and (d) Fe-15at.\%Nb samples Fe-15at.\%Nb samples with stearic acid PCA at 80 hours MA. 

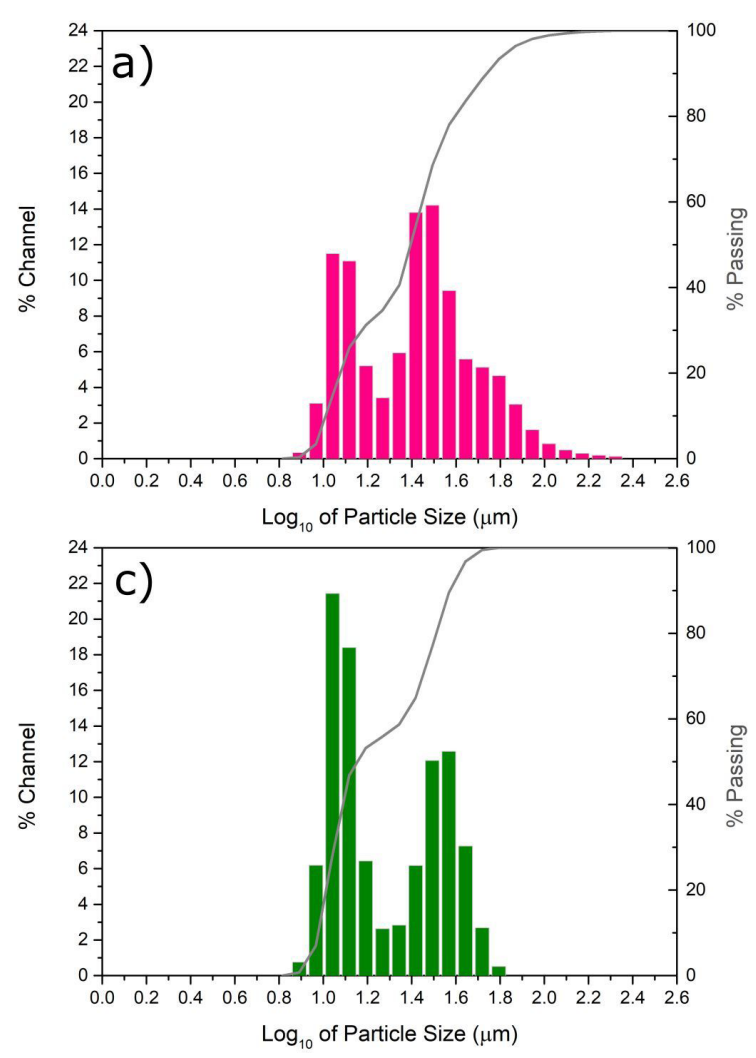
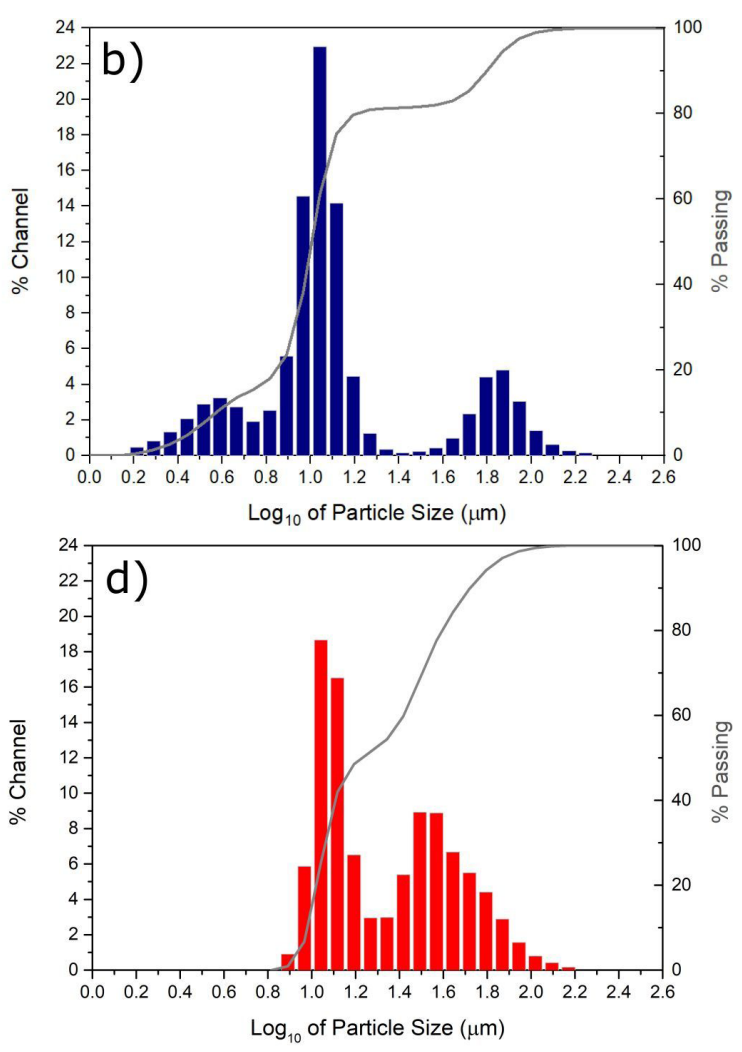

Figure 6. Particle size distribution for each alloy condition (a) Fe-15at.\%Nb samples without PCA (reference), (b) Fe-15at.\%Nb samples with methanol PCA, (c) Fe-15at.\%Nb samples with hexane PCA and (d) Fe-15at.\%Nb samples with stearic acid PCA for 80 hours MA.

with reduced crystal size, and increased micro-deformation, the peaks were also displaced to the left, changing for smaller angles, related to increased lattice parameters.

From Figure 9 we verified that the MA process causes quick crystallite size reductions in the initial stages. At $20 \mathrm{~h}$ MA this was reduced from $35.0 \pm 1.0 \mathrm{~nm}$ to $5.5 \pm 1.0 \mathrm{~nm}$ and remained in this range.

There was a progressive increase up to $40 \mathrm{~h}$ MA for the lattice parameter, from $2.025 \pm 0.005 \AA$ to approximately $2.059 \pm 0.005 \AA$, possibly due to $\mathrm{Nb}$ atoms dissolving with the Fe lattice, along with accumulated defects, coming from permanent ball collisions and powder fractures, Figure 9.

Figure 10 shows the X-ray diffractogram of the Fe15 at. $\% \mathrm{Nb}$ alloy milled with methanol PCA. Besides the $\mathrm{Fe}-\alpha$ phase, we identified a $\mathrm{Nb}$ solid solution at 20,40 and 60 milling hours, which was not observed at 80 hours.

For the methanol PCA sample, Figure 11, shows that the peak intensity at 20 hours is well defined. As milling continues, it becomes wider and dislocates to lower angles. When the milled powder is more deformed, not only can the grain size be reduced to nanometric dimensions, but the long-range and short-range orders simultaneously decrease, leading to nanocrystalline phase formation and then, eventually, an amorphous phase ${ }^{42}$.

Figure 12 shows gradual crystallite size reductions, from $35.0 \pm 1.0 \mathrm{~nm}$, to $14.0 \pm 1.0 \mathrm{~nm}$ at 20 hours, $6.0 \pm 1.0 \mathrm{~nm}$ at 40 hours, and finally to $5.0 \pm 1.0 \mathrm{~nm}$ at the final stage. In general, all samples with PCA tendered to gradually reduce crystallite size, with more significant reductions after

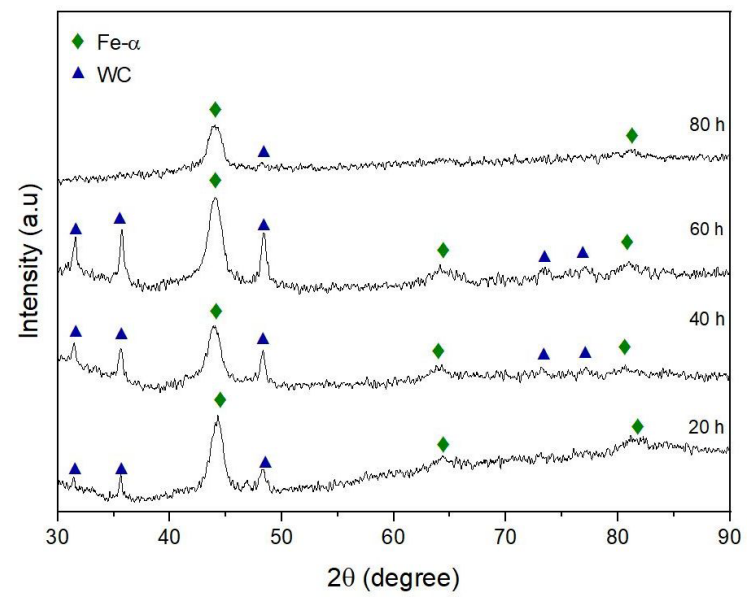

Figure 7. Fe-15at.\%Nb sample diffractogram after milling without added PCA.

40 hours. This shows that samples required more time and energy to amorphization.

Lattice parameter values increased until 60 hours, reaching $2.045 \pm 0.005 \AA$. Nonetheless, this later reduced to approximately $2.036 \pm 0.005 \AA$. This is possibly caused by recuperation, and/or recrystallization, due to increased process temperatures ${ }^{7,55}$.

Figure 13 shows the $\mathrm{X}$-ray diffractogram for the Fe-15at.\%Nb alloy milled with hexane PCA. The Fe- $\alpha$ and 
$\mathrm{Nb}_{\mathrm{sS}}$ phases appeared after 20 hours of MA and remained in crystal form until 60 hours. At 80 hours only the most intense $\mathrm{Fe}-\alpha$ peak with low crystallinity is present.

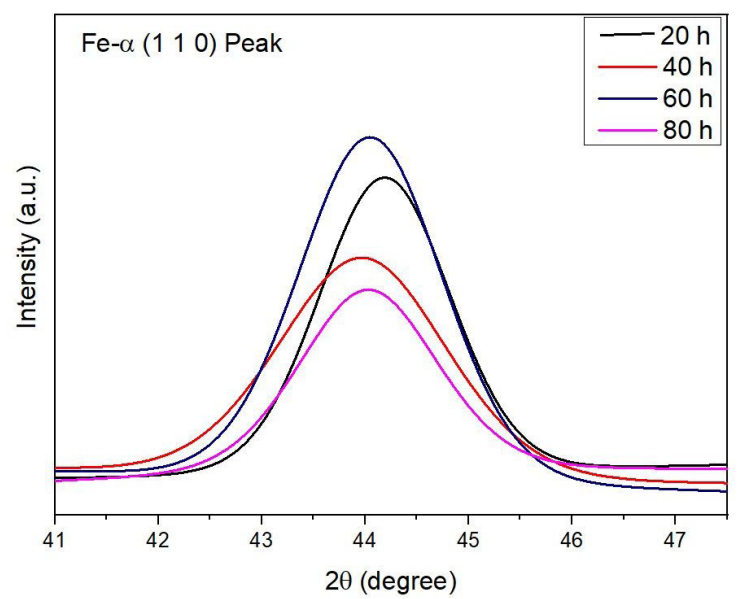

Figure 8. Detail of the (110) Fe- $\alpha$ peak analysis for different milling times for $\mathrm{Fe}-15$ at.\% $\mathrm{Nb}$ samples without PCA (reference).

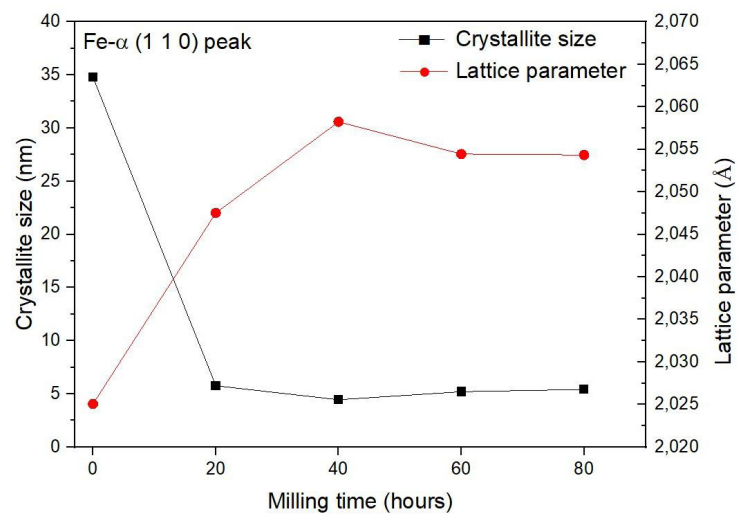

Figure 9. Crystallite size and lattice parameter as a function of different milling times for the (110) $\mathrm{Fe}-\alpha$ peak for $\mathrm{Fe}-15 \mathrm{at} . \% \mathrm{Nb}$ samples without PCA (reference).

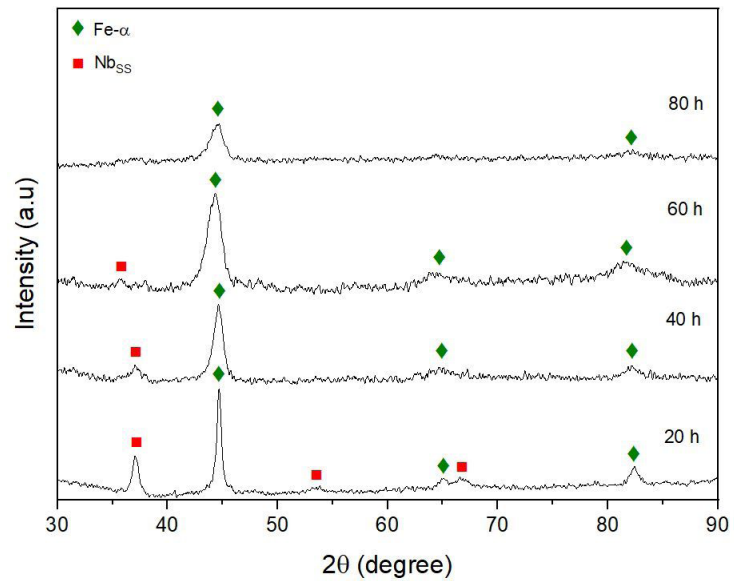

Figure 10. Fe-15at.\%Nb sample diffractogram after milling with methanol PCA.
The Fe- $\alpha$ (110) peak showed similar behavior to samples without PCA. It increased intensity at $60 \mathrm{~h}$ and displaced the lattice parameter for lower angles (Figure 14).

Among the PCAs analyzed, the hexane PCA sample showed the fastest crystallinity losses in initial stages (Figure 15), from $35.0 \pm 1.0 \mathrm{~nm}$, reducing to $7.5 \pm 1.0 \mathrm{~nm}$ at 20 hours and 40 hours, and finally to $4.5 \pm 1.0 \mathrm{~nm}$ in final stages.

Lattice parameter values increased up to 40 hours, at $2.033 \pm 0.005 \AA$ for $20 \mathrm{~h}$, and $2.055 \pm 0.005 \AA$ for $40 \mathrm{~h}$. As was the case with methanol (Figure 12), there was a subtle reduction of lattice parameter values at $60 \mathrm{~h}$ and $80 \mathrm{~h}$, $2.053 \pm 0.005 \AA$, and $2.045 \pm 0.005 \AA$, respectively. This is possibly caused by recuperation, and/or recrystallization, in the same sense of the sample containing methanol (Figure 12) (7,55. $^{\text {. }}$

The diffractogram in Figure 16 shows the alloy milling with stearic acid PCA. As in sample without PCA, this sample showed WC contamination, justified by solid state PCA not being able to protect the whole powder surface during milling as efficiently as methanol and hexane, resulting in contamination.

Of all Fe- $\alpha$ (110) peaks at $20 \mathrm{~h}$, the stearic acid sample had the highest intensity and lowest enlargement (Figure 17). At $40 \mathrm{~h}$ we verified an enlarged $\mathrm{Fe}-\alpha$ peak, and at $60 \mathrm{~h}$ its

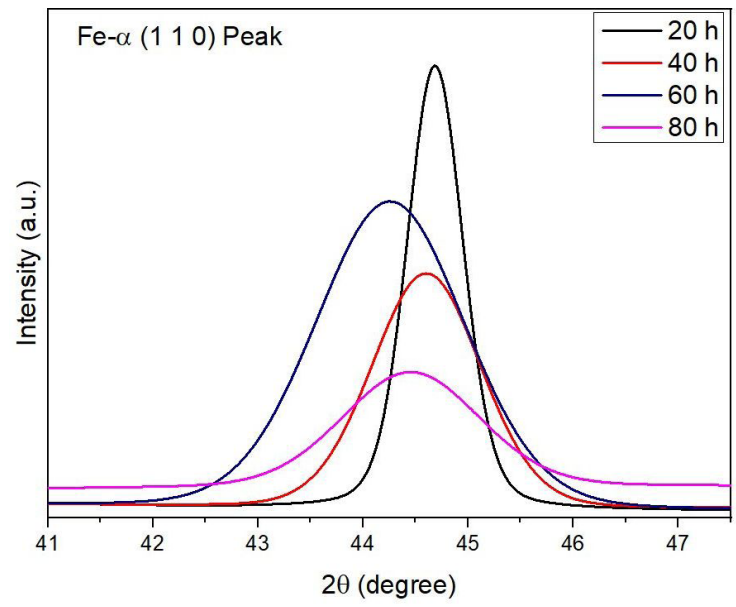

Figure 11. Detail of the (110) Fe- $\alpha$ peak analysis for different milling times for Fe-15at.\%Nb samples with methanol PCA.

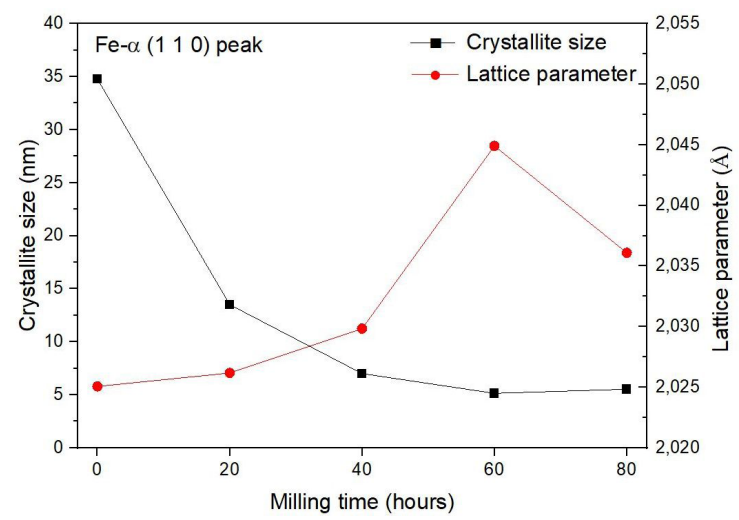

Figure 12. Crystallite size and lattice parameter as a function of different milling times for the (110) Fe- $\alpha$ peak for $\mathrm{Fe}-15 \mathrm{at} . \% \mathrm{Nb}$ samples with methanol PCA. 
displaced to the left, and was even more enlargement, due to $\mathrm{Nb}$ atom insertion into the Fe bcc structure, increasing the lattice parameter. At $80 \mathrm{~h}$ the peak flattens, showing amorphization.

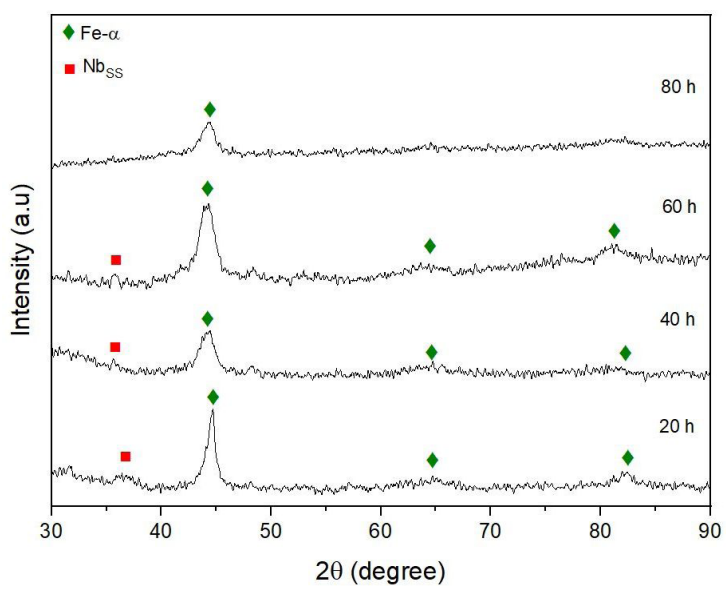

Figure 13. Fe-15at.\%Nb sample diffractogram after milling with hexane PCA.

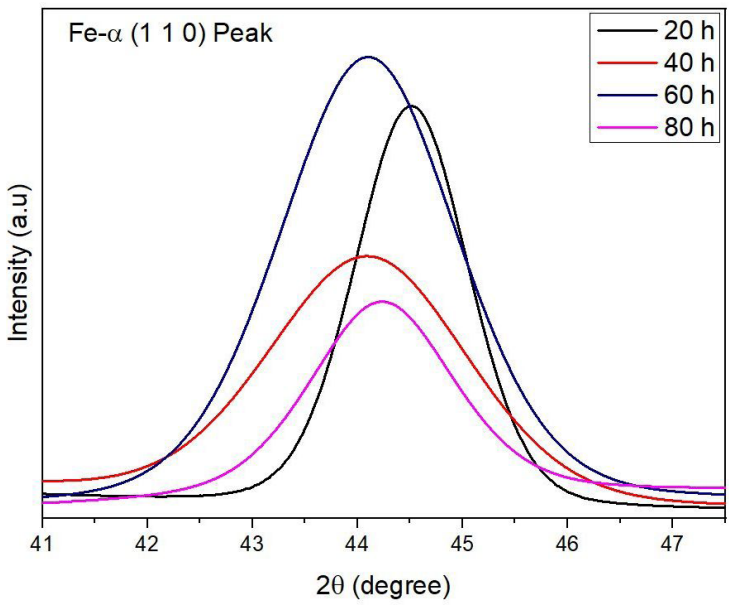

Figure 14. Detail of the (110) Fe- $\alpha$ peak analysis for different milling $\mathrm{Fe}-15 \mathrm{at} . \% \mathrm{Nb}$ samples with hexane PCA.

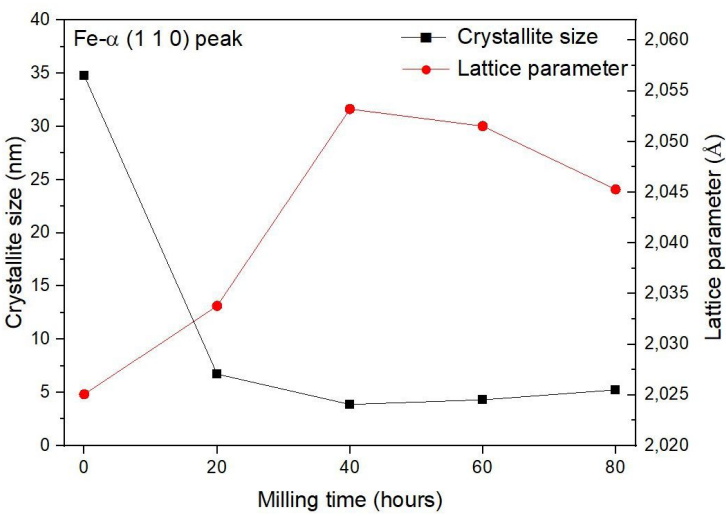

Figure 15. Crystallite size and lattice parameter as a function of different milling times for the (110) Fe- $\alpha$ peak for Fe-15at.\% $\%$ b samples with hexane PCA.
Figure 18 shows a significant reduction of crystallite size up to $40 \mathrm{~h}$, starting at $35.0 \pm 1.0 \mathrm{~nm}$, changing to $27.0 \pm 1.0 \mathrm{~nm}$ for $20 \mathrm{~h}, 7.0 \pm 1.0 \mathrm{~nm}$ at 40 hours. After this

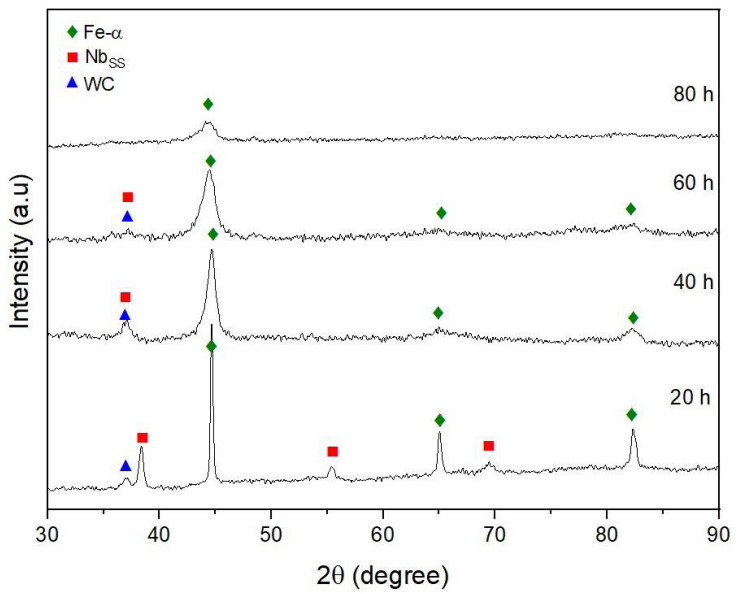

Figure 16. Fe-15at.\%Nb sample diffractogram after milling with stearic acid PCA.

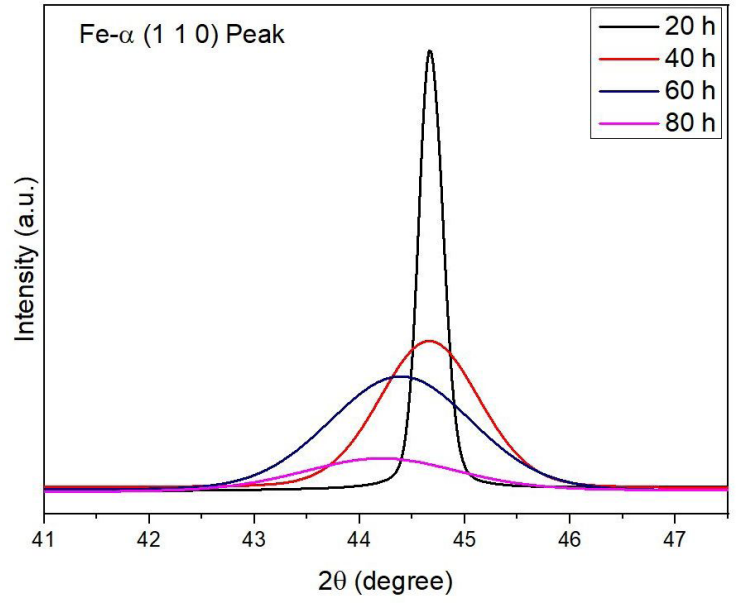

Figure 17. Detail of the (110) Fe- $\alpha$ peak analysis due to different milling times for $\mathrm{Fe}-15 \mathrm{at} . \% \mathrm{Nb}$ samples with stearic acid PCA.

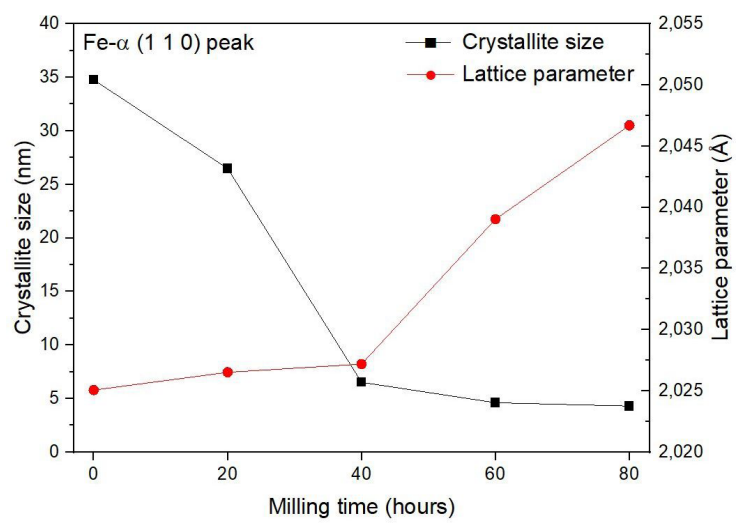

Figure 18. Crystallite size and lattice parameter as a function of different milling times for the (110) Fe- $\alpha$ peak for Fe-15at.\% $\mathrm{Nb}$ samples with stearic acid PCA. 
period, values reduce at a constant rate, with $5.0 \pm 1.0 \mathrm{~nm}$ at $60 \mathrm{~h}$ and $4.0 \pm 1.0$ at $80 \mathrm{~h}$.

Lattice parameter values increased substantially after 60 hours, increasing from $2.026 \pm 0.005 \AA$ at $40 \mathrm{~h}$ to $2.039 \pm 0.005 \AA$ at 60 , and $2.047 \pm 0.005 \AA$ at $80 \mathrm{~h}$.

\section{Conclusions}

The effects for each PCA were investigated systematically via a milling process. The morphological and granulometric analysis showed smaller average particles sizes, and smaller agglomerate formations for the material milled with PCA methanol, with particles approximately $(19.81 \pm 0.21) \mu \mathrm{m}$, better granulometric distribution, and less cold welding.

The sample without added PCA and with solid PCA (stearic acid) showed WC contamination from tungsten spheres. Due to high friction in milling, liquid PCA (methanol and hexane) showed more efficient results because it was absorbed by the whole powder surface, protecting against contamination.

We presented the changes in crystallite size and the lattice parameter for each sample in the analyzed Fe- $\alpha$ peak as a function of milling time with and without PCA. We verified that the sample with methanol PCA showed the greatest crystallinity reduction rate.

\section{Acknowledgments}

This work was conducted with the financial support of CAPES, for which the authors are grateful.

We would like to thank the Höganäs Company for providing the Fe powders used in this study.

We would like, also to thank Professor José Marcos Sasaki from Physics Department of Federal University of Ceará that kindly helped us applying Scherrer method.

\section{References}

1. Suryanarayana C, Al-Joubori AA. Synthesis of stable and metastable phases in the Ni-Si system by Mechanical Alloying. Powder Technol. 2016;302:8-14.

2. Suryanarayana C. Mechanical alloying: a novel technique to synthesize advanced materials. Research. 2019;2019:4219812.

3. Herrera-Ramirez JM, Tejeda-Ochoa A, Kametani N, CarreñoGallardo C, Ledezma-Sillas JE, Adachi N, et al. Formation of a metastable fcc phase and high Mg solubility in the Ti-Mg system by mechanical Alloying. Powder Technol. 2020;374:348-52.

4. Suryanarayana C. Phase formation under non-equilibrium processing conditions: rapid solidification processing and mechanical alloying. J Mater Sci. 2018;53:13364-79.

5. Suryanarayana C. Mechanical alloying and milling. Prog Mater Sci. 2001;46:1-184.

6. Sherif El-Eskandarany M. Mechanical alloying for fabrication of advanced engineering materials. Norwich: Noyes publications; 2001.

7. El-Eskandarany MS. Mechanical Alloying: energy storage protectice coatings, and medical applications. 3rd ed. Amsterdam: Elsevier; 2020.

8. Silva A. Thermodynamic modeling and critical experiments on the Al-Fe-Nb system [thesis]. São Paulo: Universidade de São Paulo (USP); 2015.

9. Silva AAAP, Lamoglia MS, Silva G, Fiorani J, David N, Vilasi $\mathrm{M}$, et al. Heat capacity measurements of the Fe2Nb and Fe 7Nb6 intermetallic compounds. J Alloys Compd. 2021; 878:160411.
10. Yang JY, Zhang TJ, Cui K, Li XG, Zhang J. Amorphization of Fe-Nb by mechanical Alloying. J Alloys Compd. 1996;242:1536.

11. El-Eskandarany MS, Bahgat AA, Gomaa NS, Eissa NA Kinetics and formation mechanism of amorphous $\mathrm{Fe}_{52} \mathrm{Nb}_{48}$ alloy powder fabricated by mechanical Alloying. J Alloys Compd. 1999;290:181-90.

12. Jartych EZ, Oleszak D, Zurawicz K. Hyperfine interactions in amorphous Fe-Nb alloyings prepared by mechanical alloying. Hyperfine Interact. 2001;136:25-33.

13. Povctugar IV, Butyagin PYU. Mechanical alloying of Fetransition metal systems: the analysis of different stages. J Mater Sci. 2004;39:5461-5.

14. Roy M. Synthesis and magnetic properties of laves phase $\mathrm{Fe}_{2} \mathrm{Nb}$ amorphous alloying. Solid State Commun. 2007;141:649-52.

15. Vélez GY, Alcázar GAP, Zamora LE, Tabares JA. Effect of the preparation method on the structural and magnetic properties of the $\mathrm{Fe}_{2} \mathrm{Nb}$ alloy. Cryst Res Technol. 2013;48(7):423-9.

16. Vélez GY, Alcázar GAP, Zamora LE, Tabares JA. Structural and magnetic study of the $\mathrm{Fe}_{2} \mathrm{Nb}$ alloy obtained by mechanical alloying and sintering. J Supercond Nov Magn. 2014;27:127983.

17. Vélez GY, Alcázar GAP, Zamora LE. Influence of atomic ordering on the $\mathrm{Fe}_{2} \mathrm{Nb}$ antiferromagnetic alloy. J Magn Magn Mater. 2014;354:333-5.

18. Blázquez JS, Ipus JJ, Conde CF, Conde A. Evolution of Fe environments in mechanically alloyed $\mathrm{Fe}-\mathrm{Nb}-(\mathrm{B})$ compositions. J Alloys Compd. 2014;615:S555-8.

19. Blázquez JS, Manchón-Gordón AF, Ipus JJ, Conde CF, Conde A. Evolution of $\mathrm{Fe}$ environments and phase composition during Mechanical amorphization of $\mathrm{Fe}_{70} \mathrm{Zr}_{30}$ and $\mathrm{Fe}_{70} \mathrm{Nb}_{30}$ alloys. $\mathrm{J}$ Non-Cryst Solids. 2018;494:78-85.

20. Shaw L, Zawrah M, Villegas J, Luo H, Miracle D. Effects of process control agents on mechanical alloying of nanostrctured aluminium alloys. Metall Mater Trans, A Phys Metall Mater Sci. 2003;34:159-70.

21. Nouri A, Wen C. Surfactants in mechanical alloying/milling: a catch-22 situation. Crit Rev Solid State Mater Sci. 2014;39:81108 .

22. Burmeister CF, Kwade A. Process engineering with planetary ball mills. Chem Soc Rev. 2013;42:7660.

23. Suryanarayana C. Mechanical alloying and milling. Prog Mater Sci. 2001;46:1-184.

24. See KK. Singh, C. Mandal, R.R. Prasad, P.P. Sengupta \& A. Saxena, An expert system for selection of wear resistant materials for steel plant application, J. Mater. Ed. 38, 25-36 (2016).

25. Singh KK, Mandal C, Kumar S. An expert system based approach for selection of wear resistant materials for steel plant application In: National Conference on Advanced Materials, Manufacturing and Metrology (NCAMMM - 2018); 2018 Feb 16-17; Durgapur. Proceedings. Durgapur: CSIR-CMERI.

26. Liu S, Hallstedt B, Music D, Du Y. Ab initio calculations and thermodynamic modeling for the $\mathrm{Fe}-\mathrm{Mn}-\mathrm{Nb}$ system. Calphad. 2012;38:43-58.

27. Villars P, Calvert LD. Pearson's Handbook of crystallographic data for intermetallic phases. 2nd ed. Materials Park: ASM international; 1991.

28. Voß S, Palm M, Stein F, Raabe D. Phase equilibria in the Fe-Nb system. J Phase Equilibria Diffus. 2011;32:97-104.

29. Adamek G. Influence of type of alcohol as the Process Control Agent on Ti-20Ta-20Nb alloy preparation by mechanical alloying. Acta Physica Polonica A. 2014;126(4):60-965.

30. Gonçalves VS, Rocha CJ, Leal RM No. Mechanical activation of $\mathrm{Nb} 75 \mathrm{Al}$ powder mixtures with different process control agents. Mater Sci Forum. 2008; 591-593:160-7.

31. Zhang L, Guo X. Effects of process control agents on the mechanical alloying behavior of Nb-Ti-Si based alloy. Mater Trans. 2018;59(4):528-37. 
32. Gheisari K, Javadpour S. The effect of process control agent on the structure and magnetic properties of nanocrystalline mechanically alloyed $\mathrm{Fe}-45 \%$ Ni powders. J Magn Magn Mater. 2013;343:133-7.

33. Abd Hamid SB, Eaqub Ali M, Ullah M. Structure-controlled nanomaterial synthesis using surfactant-assisted Ball Milling- a review. Curr Nanosci. 2014;10:344-54.

34. Nouri A, Hodgson PD, Wen CE. Study on the role of stearic acid and ethylene-bis-stearamide on the mechanical alloying of a biomedical titanium based alloy. Metall Mater Trans, A Phys Metall Mater Sci. 2010;41:1409-20.

35. ICDD: International Center for Diffraction Data. The phases were identified by comparing the peak positions and intensities with those listed in the International Center for Diffraction Data (ICDD). Newtown, PA, USA: ICDD; 2021 [cited 2021 Feb 23]. Available from: https://www.icdd.com/

36. Kraus W, Nolze G. PowderCell for Windows (version 2.3). Berlin: Federal Institute for Materials Research and Testing; 1999.

37. Villars P, Okamoto H, Cenzual K. ASM alloy phase diagram database. Materials Park: ASM International; 2006.

38. Muniz FTL, Miranda MAR, Santos CM, Sasaki JM. The Scherrer equation and the dynamical theory of X-ray diffraction. Acta Crystallogr A. 2016;72:385-90.

39. Miranda MAR, Sasaki JM. The limit of application of the Scherrer equation. Acta Crystallogr A Found Adv. 2018;A74:54-65.

40. Barbedo EL, Gonçalves PH, Lamoglia MS, Pontes AMP, Kuffner BHB, Gomes GF, Silva G. Analysis of milling efficiency of the Vanadis ${ }^{\circledR} 8$ tool steel with additions of vanadium and molybdenum carbides. Mater Res. 2021;24(5):e20210054.

41. James, W. The optical principles of the diffraction of x-rays. London: Bell; 1962.

42. Sheibani S, Ataine A, Heshmati-Manesh S. Role of process control agent on synthesis and consolidation behavior of nanocrystalline copper produced by mechano-chemical route. J Alloys Compd. 2008;465:78-82.

43. Vijay R, Anas NS, Ramakrishna M, Dash RK, Tata N. Rao, Influence of process control agents on microstructure and mechanical properties of $\mathrm{Al}$ alloy produced by mechanical alloying. Mater Sci Eng A. 2019;751:171-82.

44. Jayasree R, Mane RB, Vijay R, Chakravarty D. Effect of process control agents on mechanically alloyed A10.3CoCrFeNi. Mater Lett. 2021;292:129618.

45. Othman AR, Sardarinejad A, Masrom AK. Effect of milling parameters on mechanical alloying of aluminum powders. Int J Adv Manuf Technol. 2015;292:129618.

46. Espinoza-Beltrán FJ, Morales-Hernández J, Velázquez-Salazar J, García-González L, Espinoza-Beltránc FJ, Barceinas-Sánchez JDO, et al. Structure and thermal stability of ball milled Ti-Al-H powders. J Alloys Compd. 2005;388:266-73.

47. German RM. Powder metallurgy Science . 2nd ed. Princeton: Metal Powder Industries Federation; 1994.

48. Hennart SLA, VanHee P, Drouet V, Domingues MC, Wildeboer WJ, Meesters GMH. Characterization and modeling of a submicron milling process limited by agglomeration phenomena. Chem Eng Sci. 2012;71:484-95.

49. Cao G, Fadda S, Cincotti A, Concas A, Pisu M. Modelling breakage and reagglomeration during fine dry grinding in ball milling devices. Powder Technol. 2009;194:207-16.

50. Funk JE, Dinger DR. Predictive process control of crowded particulate suspensions: applied to ceramic manufacturing. Boston: Springer; 1994.

51. Suryanarayana C, Norton MG. X-ray diffraction: a practical approach. New York: Plenum; 1998.

52. Pearson WB. A handbook of lattice spacings and structures of metals and alloys. New York: Pergamon Press; 1967.

53. Matuła I, Zubko M, Dercz G. Role of Sn as a process control agent on mechanical alloying behavior of nanocrystalline titanium based powders. Materials. 2020;13(9):2110.

54. Ipus JJ, Blázquez JS, Franco V, Lozano-Pérez S, Conde A. Role of starting phase of boron on the mechanical alloying of FeNbB composition. J Alloys Compd. 2013;553:119-24.

55. Khozani BN, Abuchenari A. Effects of $\mathrm{Mg}$ and $\mathrm{MgO}$ nanoparticles on microstructural and mechanical properties of aluminum matrix composite prepared via mechanical alloying. J Alloys Compd. 2021;3:91-8. 